\title{
Comprehensive approach to Chiari malformation in pediatric patients
}

Jeremy Greenlee, M.D., P. Charles Garell, M.D., Nicholas Stence, and Arnold H. Menezes, M.D. Division of Neurosurgery, and College of Liberal Arts, University of Iowa, Iowa City, Iowa

Chiari malformation is a developmental disorder that is often associated with other abnormalities of the cerebrospinal axis. Despite widespread recognition of this association, there is relatively little information on the treatment of these coexisting disorders in the setting of cerebellar tonsillar ectopia. In an effort to improve the care provided to pediatric patients with Chiari malformations the authors reviewed their management practices over the last 20 years. Specifically, they recorded presenting symptoms, radiological studies, comorbidities, and management (surgical and nonsurgical) of 112 patients (all $<20$ years of age) with Chiari malformation without myelodysplasia.

They found an associated syrinx in $29 \%$ of patients, basilar invagination in $17 \%$, and scoliosis in $14 \%$. The basal angle varied from 120 to $190^{\circ}$ and Boogard's angle varied from 120 to $220^{\circ}$; both angles were larger than those measured in normal controls. The vertical height of the posterior fossa was shortened and the volume decreased as compared with normal controls.

The surgical management of this group of patients included posterior decompressive (44\%), combined transoral and posterior decompressive (31\%), combined posterior decompressive and posterior fusion $(8 \%)$, and multiple posterior decompressive procedures in the same patient $(5 \%)$.

The authors conclude that pediatric patients with a Chiari malformation should be specifically examined for evidence of additional craniovertebral malformations so that procedures are directed at correcting both the comorbidities and the herniation of the cerebellar tonsils through the foramen magnum.

\section{Key Words * Chiari malformation * pediatric patient * posterior cranial fossa}

The Chiari malformation falls in a spectrum of developmental anomalies and is often associated with other malformations of the craniospinal axis. $[5,8,17]$ Although the recognition of these associated abnormalities is clearly evident in the neurosurgical literature, it is not as obvious that treatment is directed with this fact in mind. At the University of Iowa, we have maintained a physiological approach to the surgical treatment of patients with craniovertebral malformations; accordingly, we tailor the interventions to each patient's underlying and associated disease.[15] In the case of patients with Chiari malformations, interventions usually include decompressive surgery, via a suboccipital craniotomy to 
relieve compression in the posterior fossa, but may also require fusion of the craniovertebral junction $(\mathrm{CVJ})$ and/or an anterior decompressive procedure to achieve the most complete treatment for individual patients.

In reviewing the literature, we found numerous descriptions of the treatment of Chiari malformations via different posterior approaches, and posterior decompressive surgery was the overwhelming mainstay of therapy. However, we located only three previously published reports in which a total of 23 patients with Chiari malformation had undergone surgery via anterior approaches, excluding those from our institution. $[2,6,14]$ In only six of those 23 patients was a combination of anterior and posterior procedures performed. Other authors have reported using anterior approaches in patients with basilar invagination, but in these patients an adjunct diagnosis of Chiari malformation had not been made. $[4,11,12,19]$

Therefore, given the paucity of data on this subject, we report the presentation and management of pediatric patients with Chiari malformations without myelodysplasia treated at our institution over the last 20 years.

\section{CLINICAL MATERIAL AND METHODS}

Patients with a Chiari malformation were identified by reviewing the Medical Records Department database as well as the Division of Neurosurgery, Craniovertebral Junction Database, which is a prospective collection of parameters obtained in patients in whom abnormalities of the CVJ have been recorded since 1979. Search criteria were limited to those patients under the age of 20 years, in whom there was no evidence of myelodysplasia and in whom magnetic resonance (MR) images of the posterior fossa had been obtained prior to neurosurgical intervention.

Medical records were reviewed for presenting signs and symptoms, as well as diagnoses of additional developmental abnormalities. Plain skull x-ray films were used to measure Boogard's angle, basal angle, and the distance of the odontoid tip from Chamberlain's line (Fig. 1).[3]

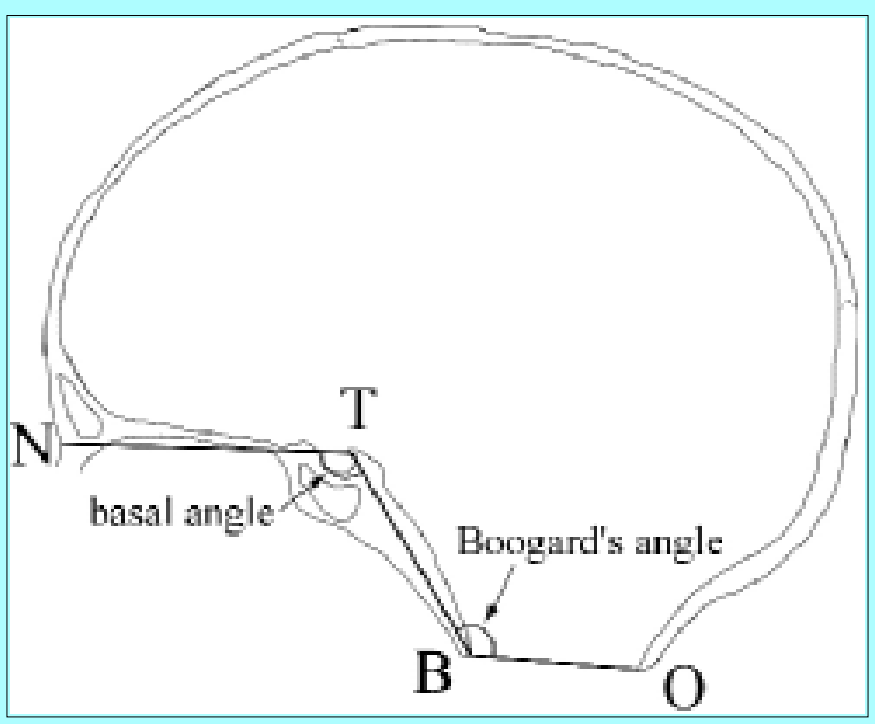

Fig. 1. Schematic drawing illustrating sagittal section of skull. The basal angle (nasion-tuberculum sella-basion) and Boogard's angle (tuberculum sella-basion-opisthion) are shown. Chamberlain's line (hard palate-opisthion) is not shown. $\mathrm{N}=$ nasion, $\mathrm{T}=$ tuberculum sella, $\mathrm{B}=$ basion, $\mathrm{O}=$ opisthion. 
In a subset of patients the volume of the posterior cranial fossa was obtained by measuring the maximum width of the bony posterior cranial fossa (x), the distance from the posterior clinoid process to the torcular herophili (y), and the distance from basion to the peak of the tentorium cerebelli $(\mathrm{z})$ on $\mathrm{T}_{1}$-weighted MR images (Fig. 2).
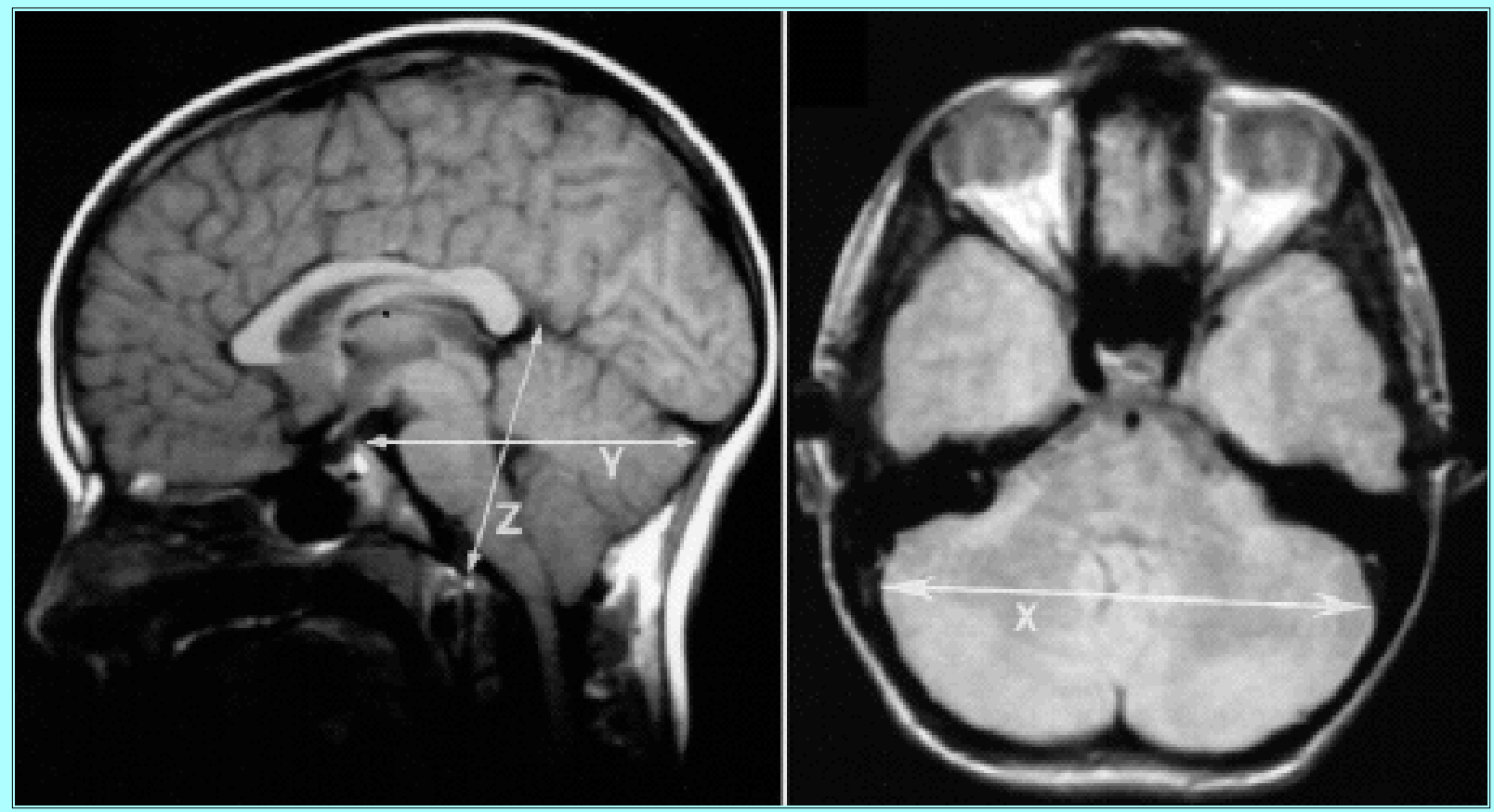

Fig. 2. Magnetic resonance imaging studies. A midsagittal (left) section from an MR image that was used to measure the height of the posterior fossa $(\mathrm{z})$ and the anterior-posterior dimension (y). An axial image (right) was used to measure the width of the posterior fossa $(\mathrm{x})$.

To construct an accurate, yet reproducible, model of the posterior fossa volume, we used the aforementioned easily identified landmarks to calculate the volume with the formula:

Fosterior cranial fosa volume $=413 \times \mathrm{FI} \times(\mathrm{X} / 2 \times \mathrm{Y} / 2 \times \mathrm{Z} / 2)$

The same linear measurements and posterior cranial fossa volume calculation was obtained in a set of normal control patients in the same age group who underwent MR imaging for an unrelated diagnosis. The significance of comparisons was determined using Student's t-test.

\section{RESULTS}

In our search 112 patients were identified with Chiari malformations who fit the inclusion criteria. Of these, 59 patients were treated surgically. The most common presenting symptom in the overall group was headache and/or neck pain (27\%; Table 1$)$, which was followed by weakness $(12 \%)$, dysphagia $(8 \%)$, and scoliosis $(7 \%)$. 


\begin{tabular}{|lc|}
\hline \multicolumn{2}{|c|}{ TABLE 1 } \\
\multicolumn{2}{|c|}{$\begin{array}{c}\text { PRESENT NG SVMPTOMS IN 112 PATIENTS WITH } \\
\text { CHIARI MALFORMATION }\end{array}$} \\
\hline \hline \multicolumn{1}{|c|}{ Symptom } & No. of Patients (\$) \\
\hline headache hed pain & $30(27)$ \\
weakness & $13(12)$ \\
dysphagia & $9(8)$ \\
scoliosis & $8(7)$ \\
spasticity & $7(6)$ \\
numbness & $7(6)$ \\
incoordination & $6(5)$ \\
sleep apnea & $5(4)$ \\
nauseahomiting & $5(4)$ \\
torticollis & $2(2)$ \\
other & $26(23)$ \\
\hline
\end{tabular}

In several patients other anomalies were demonstrated in addition to a Chiari malformation (Table 2). The presence of a syrinx was the most common (32 patients, [29\%]), followed by basilar invagination in 19 patients (17\%), scoliosis in 16 patients (14\%) and Klippel-Feil syndrome in nine patients (8\%).

\begin{tabular}{|cc|}
\hline \multicolumn{2}{|c|}{ TABLE 2 } \\
\multicolumn{2}{|c|}{ ADD TONAL DIAGNOSES IN PATIENTS WITH } \\
CHIARI MaLFORMATION \\
\hline \hline Diagnosis & No. of Patients (\%) \\
\hline Syrinx & $32(29)$ \\
basilar invagination & $19(17)$ \\
scoliosis & $16(14)$ \\
Klippel-Feil syndrome & $9(8)$ \\
CWJinstability & $4(4)$ \\
hydrocephalus & $3(3)$ \\
other & $12(11)$ \\
\hline
\end{tabular}

Skull radiography revealed the mean basal angle to be $147^{\circ}\left( \pm 12^{\circ}\right.$; range $128-190^{\circ}$; Fig. 3 upper left $)$.

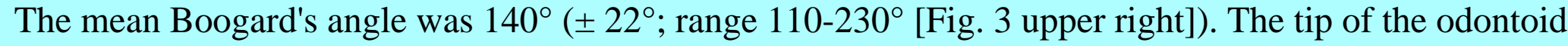
process averaged $0.4 \mathrm{~mm}$ below Chamberlain's line but had a standard deviation of $7.8 \mathrm{~mm}$ (range -20 to $23 \mathrm{~mm}$, with the negative value indicating that the tip of the odontoid was inferior to Chamberlain's line; [Fig. 3 lower]). 

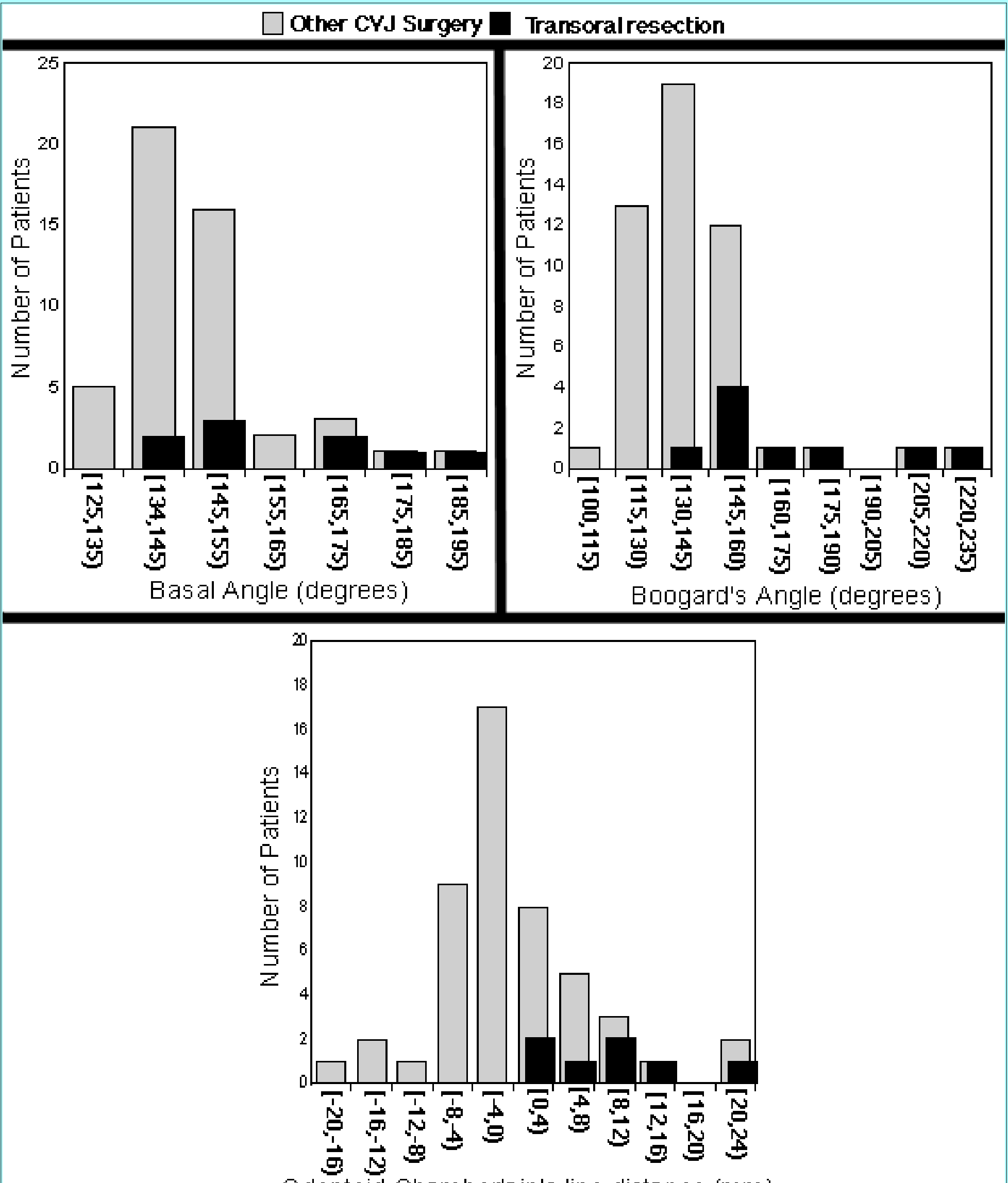

Odontoid-Chamberlain's line distance (mm)

Fig. 3. Histograms. Upper left: Distribution of the basal angle relative to surgical procedure. A higher percentage of patients with increased basal angles underwent transoral resection. Upper right: Distribution of Boogard's angle relative to surgical procedure. Every case with 
an angle greater than $160^{\circ}$ was treated by a transoral resection. Lower: Distribution of the tip of the odontoid relative to Chamberlain's line. No patient with an odontoid tip located below Chamberlain's line underwent transoral resection. As the odontoid rises above Chamberlain's line, the incidence of transoral decompression increases.

The volume of the posterior cranial fossa was significantly smaller in patients with a Chiari malformation as compared with normal controls $(\mathrm{p}<0.001)$. In the 15 patients in whom these data were measured there was a mean volume of $259 \pm 41 \mathrm{~cm}^{3}$ (range $187-323 \mathrm{~cm}^{3}$ ) whereas in the 10 control participants there was an average volume of $355 \pm 46 \mathrm{~cm}^{3}$ (range 274-415 $\mathrm{cm}^{3}$ ); there was no correlation between posterior cranial fossa volume and age (range 5-19 years) in this group of patients (data not shown). There was no significant difference in the width of the posterior cranial fossa or the posterior clinoid-torcular herophili distance; however, the basion-peak of the tentorium cerebelli distance was significantly shorter in those with a Chiari malformation $(5.8 \pm 0.6 \mathrm{~cm})$ as compared with controls $(7.5 \pm 0.6 \mathrm{~cm} ; \mathrm{p}<0.001)$.

A significant proportion of our surgically treated patients underwent multiple procedures (Table 3). Whereas $44 \%$ of the patients underwent posterior decompressive procedure alone, $31 \%$ underwent a combination of both anterior and posterior decompressive procedures. A solitary transoral resection was performed in one patient, and in one patient a second transoral procedure was required.

\begin{tabular}{|c|c|}
\hline \multicolumn{2}{|l|}{$\begin{array}{c}\text { TABLE } 3 \\
\text { SURGKAL PROCEDURES PERFORMED IN } 59 \text { PATIENTS }\end{array}$} \\
\hline Procedure & No. of Patients (\%) \\
\hline $\begin{array}{l}\text { posterior decom pression alone } \\
\text { posterior decom pression \& ior posterior fusion \& transoral resection } \\
\text { posterior decom pression \& posterior fusion } \\
\text { mul tiple posterior decom pression } \\
\text { other } \\
\text { posterior fusion alone } \\
\text { transoral resection alone } \\
\text { mul tiple transoral resection }\end{array}$ & $\begin{array}{l}26(44) \\
18(31) \\
5(8) \\
3(5) \\
3(5) \\
2(3) \\
1(2) \\
1(2)\end{array}$ \\
\hline
\end{tabular}

\section{DISCUSSION}

This study was undertaken in an effort to gain more insight into the complexities and wide spectrum of abnormalities of the craniovertebral junction. Although we focused on patients with a Chiari malformation without myelodysplasia and who were under the age of 20 years, we found a wide range of symptomatology and pathological conditions that presented many intriguing management dilemmas.

The symptoms and multiple diagnoses reported in this series are compatible with previously published data, which suggests that our cohort of patients is representative of others with Chiari malformations and not the result of a referral bias.[7,9,13,16]

The finding of a decreased volume of the posterior cranial fossa was not unexpected because of the excellent craniometric analyses previously published.[1,10,17,18,20] Whereas some authors have calculated the volume of the posterior cranial fossa by using computerized tomography data, others have demonstrated a reduced area of the posterior cranial fossa on plain X-ray films; the results we obtained by using MR imaging reconfirm diminished volume. Interestingly, Nishikawa and associates[10] reported no significant difference in the total volume of the posterior cranial fossa observed on computerized tomography scan and MR images between patients with Chiari malformations and controls, although 
there was a difference in the ratio of neural to bony posterior cranial fossa volume. This conflicting information is understandable in light of the different formulas and methods used to calculate the volume of the posterior fossa. The method used in this report was designed to be easily and reliably performed by different investigators while maintaining a true representation of the volume of the posterior fossa.

Further investigation of the linear measurements in the $\mathrm{x}, \mathrm{y}$, and $\mathrm{z}$ planes of the posterior cranial fossa revealed that the only significant difference between patients and controls was the height of the posterior fossa (basion-peak of the tentorium cerebelli). Comparison of the posterior fossa volume to the type of surgical procedure performed, however, did not reveal any specific trend, nor did a comparison of the individual linear measurements in the $\mathrm{x}, \mathrm{y}$, and $\mathrm{z}$ planes have a bearing on surgical approach.

In our patients increased basal angles and Boogard's angles were demonstrated, as compared with those patients reported by Schady, et al.,[17] and Vega et al.,[20] in whom normal basal angles of 128 to $129.5^{\circ}$ and normal Boogard's angles of 131 to $136^{\circ}$ were present. More recently, Goel and colleagues[6] reported the basal angles in a series of patients with Chiari malformation and basilar invagination; these values were similar to those obtained in the current study.

Of importance is the finding that as the angles increased, the patient was more likely to require transoral decompressive surgery. In the case of the basal angle, the procedure was performed in four (80\%) of five patients in whom the angle was at least $165^{\circ}$ and in nine (20\%) of 44 patients in whom the angle was greater than $135^{\circ}$. Similarly, six $(67 \%)$ of nine patients with a Boogard's angle of at least $150^{\circ}$ and nine $(39 \%)$ of 23 patients with an angle of greater than $140^{\circ}$ underwent transoral surgery.

Regarding the location of the odontoid, there was considerable variability in the distance of the tip of the odontoid process in relation to Chamberlain's line, with the overall mean distance actually falling just below Chamberlain's line. However, as the tip of the odontoid was observed to be farther above Chamberlain's line, the incidence of those patients requiring an anterior decompressive procedure via a transoral resection increased. For example, all three patients in whom distances of at least $12 \mathrm{~mm}$ were measured, $60 \%$ (three of five) in whom at least $9 \mathrm{~mm}$ was measured, and 63\% (five of eight) of those in whom at least $6 \mathrm{~mm}$ above the line were measured underwent a transoral procedure. Goel and colleagues[6] reported a similar finding: transoral decompressive surgery was required in $79 \%$ of patients in whom an odontoid tip at least $13 \mathrm{~mm}$ above Chamberlain's line was measured.

The findings contained in this series have not been previously reported and are potentially important regarding the best surgical treatment of patients with Chiari malformations. Specifically, patients with an odontoid tip located above Chamberlain's line, a Boogard's angle greater than $130^{\circ}$ and a basal angle greater than $135^{\circ}$ should be considered for anterior decompressive surgery for the complete surgical treatment of their Chiari malformation. Simply performing a single decompressive surgery to treat the posterior fossa and hoping that the anteriorly located pathological process will subsequently resolve is not a comprehensive treatment plan. Instead, by performing a posterior decompressive procedure in conjunction with posterior fusion, and anterior decompressive surgery when indicated, the patient is afforded a greater chance of obtaining symptomatic relief from a single hospitalization.

\section{References}

1. Badie B, Mendoza D, Batzdorf U: Posterior fossa volume and response to suboccipital decompression in patients with Chiari I malformation. Neurosurgery 37:214-218, 1995 
2. Bindal AK, Dunsker SB, Tew JM Jr: Chiari I malformation: classification and management. Neurosurgery 37:1069-1074, 1995

3. Chamberlain WE: Basilar impression (platybasia). A bizarre developmental anomaly of the occipital bone and upper cervical spine with striking and misleading neurologic manifestations. Yale J Biol Med 11:487-496, 1939

4. Di Lorenzo N, Fortuna A, Guidetti B: Craniovertebral junction malformations. Cranioradiological findings, long-term results, and surgical indications in 63 cases. J Neurosurg 57:603-608, 1982

5. Erbengi A, Oge HK: Congenital malformations of the craniovertebral junction classification and surgical treatment. Acta Neurochir 127:180-185, 1994

6. Goel A, Bhatjiwale M, Desai K: Basilar invagination: a study based on 190 surgically treated patients. J Neurosurg 88:962-968, 1998

7. Levy WJ, Mason L, Hahn JF: Chiari malformation presenting in adults: a surgical experience in 127 cases. Neurosurgery 12:377-390, 1983

8. Muhonen MG, Menezes AH, Sawin PD, et al: Scoliosis in pediatric Chiari malformations without myelodysplasia. J Neurosurg 77:69-77, 1992

9. Nagib MG: An approach to symptomatic children (ages 4-14 years) with Chiari type I malformation. Pediatr Neurosurg 21:31-35, 1994

10. Nishikawa M, Sakamoto H, Hakuba A, et al: Pathogenesis of Chiari malformation: a morphometric study of the posterior cranial fossa. J Neurosurg 86:40-47, 1997

11. Pasztor E, Vajda J, Piffko P, et al: Transoral surgery for basilar impression. Surg Neurol 14:473-476, 1980

12. Pasztor E, Vajda J, Piffko P, et al: Transoral surgery for craniocervical space-occupying processes. J Neurosurg 60:276-281, 1984

13. Paul KS, Lye RH, Strang FA, et al: Arnold-Chiari malformation. J Neurosurg 58:183-187, 1983

14. Pillay PK, Awad IA, Little JR, et al: Symptomatic Chiari malformation in adults: a new classification based on magnetic resonance imaging with clinical and prognostic significance. Neurosurgery

28:639-645, 1991

15. Piper JG, Menezes AH: Chiari malformation in the adult, in Menezes AH, Sonntag VKH (eds): Principles of Spinal Surgery. New York: McGraw-Hill, 1996, Vol 1, pp 379-394

16. Saez RJ, Onofrio BM, Yanagihara T: Experience with Arnold-Chiari malformation, 1960 to 1970. J Neurosurg 45:416-422, 1976

17. Schady W, Metcalfe RA, Butler P: The incidence of craniocervical bony anomalies in the adult Chiari malformation. J Neurol Sci 82:193-203, 1987

18. Stovner LJ, Bergan U, Nislen G, et al: Posterior cranial fossa dimensions in the Chiari I malformation: relation to pathogenesis and clinical presentation. Neuroradiology 35:113-118, 1993 
19. Tuite GF, Veres R, Crockard A, et al: Pediatric transoral surgery: indications, complications, and long-term outcome. J Neurosurg 84:573-583, 1996

20. Vega A, Quintana F, Berciano J: Basichondrocranium anomalies in adult Chiari type I malformation: a morphometric study. J Neurol Sci 99:137-145, 1990

Manuscript received April 15, 1999.

Accepted in final form May 15, 1999.

Address reprint requests to: Arnold H. Menezes, M.D., Division of Neurosurgery, University of Iowa, Iowa City, Iowa 52242. email: Arnold-Menezes@uiowa.edu. 